$\mathrm{N}$-butyl-2-cyanoacrylate (Histoacryl) has been in use for almost 20 years for acute control of hemorrhage from gastric varices [1]. We present here a rarely reported complication associated with its use.

A 65-year-old man, who had been diagnosed 20 years previously with noncirrhotic portal hypertension due to bilharziasis, was admitted with gastric variceal bleeding. He had undergone esophageal variceal eradication in the past. The varices were injected with cyanoacrylate diluted with Lipiodol $(1.5 \mathrm{ml} / 2.1 \mathrm{ml})$. After several hours, the patient complained of chest pain and an inability to see. Investigation revealed inferior wall myocardial infarction and cortical blindness. Noncontrast computed tomography of the brain showed multiple hyperdense foci suggestive of cyanoacrylate emboli in the cerebral arteries, and bilateral occipital infarcts (Figure $\mathbf{1}$ ).

Further investigation in another center revealed that he had a patent foramen ovale (PFO). This was closed with a 25mm Amplatzer PFO-occluding device via a percutaneous approach. Following this, a transjugular intrahepatic portosystemic shunt was placed. The patient's vision improved, and he became able to perceive color, recognize faces, and count fingers at a distance of $2 \mathrm{~m}$. Two months later, he was asymptomatic.

Acute gastrointestinal bleeding from large gastric varices is an infrequent but potentially life-threatening event. Cyanoacrylate glue is increasingly being used for hemostasis in this situation [2]. Lipiodol is often used as a diluent with the glue. It prevents rapid polymerization inside the injector and makes the injection radiopaque [1].

Embolism with glue occurs in less than $1 \%$ of cases, mainly in the lungs, portal vein, heart, splenic circulation, and rarely the brain $[1,3]$. In this case, the patient did not have a pulmonary embolism, probably due to the presence of an intracar-

\title{
Cortical Blindness and Acute Myocardial Infarction Following Injection of Bleeding Gastric Varices with Cyanoacrylate Glue
}
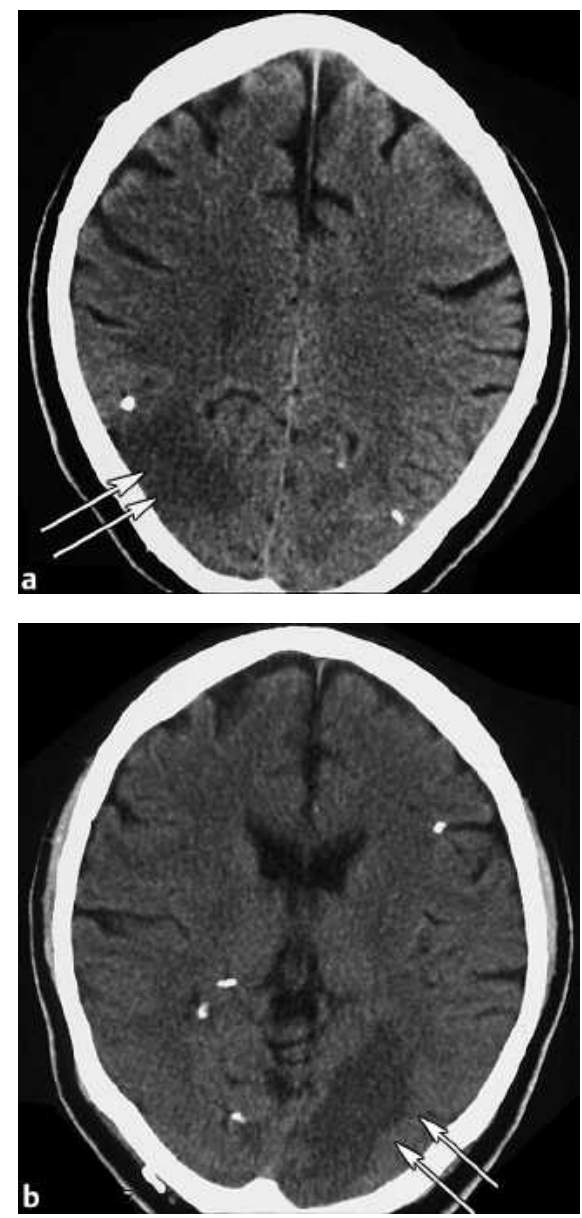

Figure 1 Computed tomography of the brain, showing an infarct in the right occipital area (a, arrows) and left occipital area (b, arrows), as well as cyanoacrylate emboli.

diac shunt. Patent foramen ovale occurs in $20-30 \%$ of adults. In most instances, it is diagnosed after episodes of paradoxical embolism [4].

Larger volumes of glue injected, fast blood flow in large vessels, and slow injection may result in fragmentation of the glue and hence embolization [2,5]. A combined radiographic/endoscopic approach for varices larger than $10 \mathrm{~mm}$, dilution of the glue with Lipiodol at ratios not exceeding $1: 1$, and even injection without admixture with Lipiodol have been suggested as methods of avoiding this [2]. Cerebral stroke is still a rare complication after the injection of cyanoacrylate. Mod- ified injection techniques might be able to prevent this potentially life-threatening complication.

\section{A. P. Upadhyay', R. Ananthasivan', \\ S. Radhakrishnan ${ }^{1}$, G. Zubaidi' \\ ${ }^{1}$ Dept. of Gastroenterology, Royal \\ Hospital, Seeb, Oman \\ 2 Dept. of Radiology, Royal Hospital, Seeb, Oman}

\section{References}

${ }^{1}$ Binmoeller KF, Soehendra N. New haemostatic techniques: Histoacryl injection, banding/Endoloop ligation and haemoclipping. Baillière's Clin Gastroenterol 1999; 13: 85-96

2 Kok K, Bond RP, Duncan IC et al. Distal embolization and local vessel wall ulceration after gastric variceal obliteration with $\mathrm{N}$-butyl-2-cyanoacrylate: a case report and review of the literature. Endoscopy 2004; 36: $442-446$

${ }^{3}$ Rösch W, Rexroth G. Pulmonary, cerebral and coronary emboli during bucrylate injection of bleeding fundic varices. Endoscopy 1998; 30: S89-S90

${ }^{4}$ Landzberg MJ, Khairy P. Patent foramen ovale. Heart 2004; 90: 219-224

${ }^{5}$ Suga T, Akamatsu T, Kawamura Y et al. Actual behavior of $\mathrm{N}$-butyl-2-cyanoacrylate (Histoacryl) in a blood vessel: a model of the varix. Endoscopy 2002; 34: $73-77$

\section{Corresponding Author}

\section{A. P. Upadhyay, D.M.}

Dept. of Gastroenterology

Royal Hospital

P.O. Box 1331

Postal Code 111

Seeb

Sultanate of Oman

Fax: $\quad$ +968-24503925

E-mail: amalupadhyay@hotmail.com 